\title{
Optimisation of Phenol Removal from Palm Oil Mill Effluent (POME) Using Natural Bentonite
}

\author{
Muhammad Said ${ }^{1 *}$, Tarmizi Taher ${ }^{1}$, Addy Rachmat $^{1}$, Poedji Loekitowati Hariani ${ }^{1}$, and \\ Aldes Lesbani ${ }^{1}$ \\ ${ }^{1}$ Department of Chemistry. Faculty of Mathematics and Natural Science. Universitas Sriwijaya. \\ Indralaya 30662. Sumatera Selatan Indonesia
}

\begin{abstract}
The adsorption of POME using natural clay. Bentonite has been investigated. The Optimization of phenol removal in various influence factors has been determined. The optimum conditions for dosage of adsorbent. contact time and $\mathrm{pH}$ are. respectively. The $\%$ removal reaches more than $85 \%$ for all parameter. The experimental data was optimized by response surface method using a second order polynomial model with Box Behken design. The optimum of parameter removal will be achieved when the dosage of adsorbent. concentration of POME and $\mathrm{pH}$ were $2.20 \mathrm{mg} / \mathrm{L}$. $70.68 \mathrm{~min}$ and 8.07. respectively. The predicted of COD value was $0.00303 \mathrm{mg} / \mathrm{L}$ which in good agreed with experiment value as 0.0297 $\mathrm{mg} / \mathrm{L}$ was obtained.
\end{abstract}

\section{Introduction}

Indonesia has been known as the world leading producer of palm oil. Along with the increasing production of palm oil. the need for water also increases. To process one ton of Fresh Fruit Bunches (FFB) required 5-7.5 tons of fresh water and unfortunately. 50\% of this water will end up as a Palm Oil Mill Effluent (POME) while the rest is lost as steam boilers and leakage. These wastewaters. if they do not get a good handling. will potentially pollute the environment [1].

Phenol and phenolic compounds are usually derived from the pulp and paper industry. wood preservation. mining and coal combustion. and also palm oil [2]. Phenol has long been known as a dangerous organic pollutant because it is harmful to organisms. even at a low concentration. Phenol is very soluble in water. oil. carbon disulphide and a variety of phenolic compounds [3]. For humans. phenol has a toxic effect that can spread rapidly by absorption through the skin and eyes. Inside the human body. phenol damages the function of the liver. kidneys. lungs. and vascular system. Due to the negative effects. the presence of phenol must be removed.

Adsorption is one of the most commonly used methods. Said et al. has conducted research using montmorillonite to reduce the COD. TSS and Colour from palm oil mill

*Corresponding author: msaidusman@unsri.ac.id 
effluent (POME. The optimum conditions for mixing speed of the stirrer. contact time. dosage of adsorbent. concentration. and pH were 300 rpm. 90 min. 5 g/L. 25\% POME and $\mathrm{pH}$ 7. respectively. The removal reached more than $95 \%$ for all parameters [4].

Although the percentage of removal was more than 95\%. there are still doubts on the validation of the value obtained. The absence of interaction between parameters becomes the cause of the invalidity of the value. Therefore we need a tool that can combine all parameters in one time the same. Response Surface Method (RSM) is a well-known tools used in data gathering and math modelling that can be used to determine the effect some independent variables on the response. RSM is very useful to improve the accuracy of output process [5].

In this experiment. we test the RSM tools to determine the optimise condition of phenol removal using natural Bentonite. In order to analyse the process. three independent variables. viz. dosage of adsorbent. $\mathrm{pH}$ of solution and contact time and also one dependent variables. viz. phenol content was studied.

\section{Material and Methods}

\subsection{Characterization of Bentonite and POME}

Natural Bentonite were supplied from Bandar Lampung. Indonesia and used as received. The sample of POME was collected from aerobic pond of palm oil mill in South Sumatera.Indonesia. The POME is saved in container and keeps in cool room at temperature $4^{\circ} \mathrm{C}$.

\subsection{Experiment Setup}

The experiment was done in $500 \mathrm{~mL}$ beakers containing of $250 \mathrm{~mL}$ of POME solution. Each of adsorption process was the combination of different variable conditions. After the adsorption is completed. the solution is sediment for 1 hour to make the adsorbent settle down and the clear solution moved to a new container to be keep or analysed parameters.

The characterisation of concentration of phenol was performed before and after treatment analysed using a portable data logging spectrophotometer DR 3900 from HACH. USA. The experiments were repeated three times. and the average values were recorded. Reductions in the parameters of the solution were calculated by the following equation:

$$
\mathrm{C}(\%)=\left(1-\frac{C f}{C s}\right) \times 100
$$

where $\mathrm{C}_{\mathrm{f}}$ is the concentration in the filtrate solution and $\mathrm{Cs}$ is the concentration in the feed sample.

The concentration of phenol in the feed sample of POME was determined prior to adsoprtion proses and the phenol concentraion was $0.752 \mathrm{mg} / \mathrm{L}$. By using the Equation 1. it can be calculated the reduction of phenol after adsorption process.

\subsection{Statistical Design of Experiments}

In this study. the Box-Behnken was used to design the experiments (DOE) by Design Expert software version 6.0. The independent variables are notated as $\mathrm{X}$ and the dependent 
variables as $\mathrm{Y}$. Determination of the DOE aims to reduce the number of experiments and obtain the optimum response $(\mathrm{Y})$ as the result of interaction of all the factors $(\mathrm{X})$ involved. In this study. the responses were concentration of phenol while the factors were concentration of POME. $\mathrm{pH}$ of solution and contact time.

After conducting the experiment. the coefficients of the polynomial model were determined using the following equation:

$$
Y=\beta_{0}+\sum_{i=1}^{k} \beta_{i} X_{i}+\sum_{i=1}^{k} \beta_{i i} X_{i}^{2}+\sum_{i=1 . i . j}^{k-1} \sum_{j=2}^{k} \beta_{i j} X_{i} X_{j}
$$

Where. $\beta_{\mathrm{o}}$ is the constant coefficient. $\beta_{\mathrm{i}}$ is the linear coefficients. $\beta_{\mathrm{ii}}$ is the quadratic coefficients. and $\beta_{\mathrm{ij}}$ is the interaction coefficients.

Three dimensional plots and two dimensional contour plots were obtained based on the effect of the interaction of the two factors. From these plots. the optimum region can be identified. The experimental and results data are shown in Table 1.

Table 1. Data of experiment and results of RSM

\begin{tabular}{|c|c|c|c|c|c|}
\hline $\begin{array}{c}\text { Run } \\
\text { No. }\end{array}$ & $\begin{array}{c}\text { Dosage of } \\
\text { Bentonite } \\
\mathbf{( m g} / \mathbf{L})\end{array}$ & $\begin{array}{c}\text { Contact } \\
\text { time } \\
\mathbf{( m i n )}\end{array}$ & $\begin{array}{c}\text { pH of } \\
\text { POME }\end{array}$ & $\begin{array}{c}\text { Conc. Of } \\
\text { Phenol } \\
\mathbf{( m g} / \mathbf{L})\end{array}$ & $\begin{array}{c}\text { Phenol } \\
\text { removal } \\
\mathbf{( \% )}\end{array}$ \\
\hline 1 & 3.50 & 75.00 & 6.00 & 0.053 & 92.95 \\
\hline 2 & 3.50 & 75.00 & 6.00 & 0.032 & 95.74 \\
\hline 3 & 5.00 & 120.00 & 3.00 & 0.071 & 90.56 \\
\hline 4 & 3.50 & 75.00 & 6.00 & 0.053 & 92.95 \\
\hline 5 & 5.00 & 30.00 & 9.00 & 0.171 & 77.26 \\
\hline 6 & 2.00 & 120.00 & 3.00 & 0.13 & 82.71 \\
\hline 7 & 5.00 & 30.00 & 3.00 & 0.091 & 87.90 \\
\hline 8 & 3.50 & 75.00 & 0.95 & 0.054 & 92.82 \\
\hline 9 & 0.98 & 75.00 & 6.00 & 0.034 & 95.48 \\
\hline 10 & 3.50 & -0.68 & 6.00 & 0.082 & 89.10 \\
\hline 11 & 5.00 & 120.00 & 9.00 & 0.066 & 91.22 \\
\hline 12 & 3.50 & 75.00 & 6.00 & 0.035 & 95.35 \\
\hline 13 & 2.00 & 120.00 & 9.00 & 0.076 & 89.89 \\
\hline 14 & 3.50 & 75.00 & 6.00 & 0.059 & 92.15 \\
\hline 15 & 3.50 & 150.68 & 6.00 & 0.062 & 91.76 \\
\hline 16 & 3.50 & 75.00 & 11.05 & 0.041 & 94.55 \\
\hline 17 & 6.02 & 75.00 & 6.00 & 0.082 & 89.10 \\
\hline
\end{tabular}

\section{Results and Discussions}

\subsection{Model Fitting of Box-Behnken Design}

The effects of POME concentration. $\mathrm{pH}$ of solution. and contact time on the phenol concentration were investigated using the quadratic polynomial model. The analysis of variance (ANOVA) results of the Box Behnken model is given in Table 2.

The final model created by the Box Behnken design involved all the coefficients. which is shown as a quadratic regression. The degree of significance of the model and all the factors (Dosage of adsorbent. Contact time. and $\mathrm{pH}$ of POME solution) are presented according to the P-value. where a value that is less than 0.050 is considered to be significant. and any other value that is greater than 0.050 is not significant. Additionally. other important terms are the accuracy and variability of the Box Behnken model. which 
can be estimated according to the R-Squared $\left(\mathrm{R}^{2}\right)$. The $\mathrm{R}^{2}$ value of the Box Behnken model was 0.9615 . On the other hand. the Adj R-Squared ( $\mathrm{R}^{2} \mathrm{adj}$ ) coefficient was also found to be 0.9121 which was so close to the $\mathrm{R}^{2}$ value. These values indicated a good correlation between the factors of the process using the Box Behnken design. However. an adequate precision term of Box-Behnken was used for evaluating the predicted range of responses relative to the associated error. An adequate precision term greater than 4 was attributed to an adequate fit to the model. The resulting adequate precision term from the Box-Behnken model used herein was 17.179. supporting the fitness of the final model.

Table 2. Anova results for quadratic model of Box Behnken

\begin{tabular}{|c|c|c|c|c|c|}
\hline Source & $\begin{array}{c}\text { Sum of } \\
\text { squares }\end{array}$ & DoF & Mean square & F-value & P-value \\
\hline Model & 0.078 & 9 & $8.717 \mathrm{E}-003$ & 19.44 & $0.0004 *$ \\
\hline $\mathrm{X}_{1}$ & $3.281 \mathrm{E}-003$ & 1 & $3.281 \mathrm{E}-003$ & 7.32 & $0.0304 *$ \\
\hline $\mathrm{X}_{2}$ & $1.513 \mathrm{E}-003$ & 1 & $1.513 \mathrm{E}-003$ & 3.37 & 0.1089 \\
\hline $\mathrm{X}_{3}$ & $2.645 \mathrm{E}-004$ & 1 & $2.645 \mathrm{E}-004$ & 0.59 & 0.4676 \\
\hline $\mathrm{X}_{1}^{2}$ & 0.011 & 1 & 0.011 & 24.45 & $0.0017 *$ \\
\hline $\mathrm{X}_{2}^{2}$ & $2.733 \mathrm{E}-003$ & 1 & $2.733 \mathrm{E}-003$ & 6.09 & $0.0429 *$ \\
\hline $\mathrm{X}_{3}^{2}$ & 0.014 & 1 & 0.014 & 32.16 & $0.0008^{*}$ \\
\hline $\mathrm{X}_{12}$ & $5.256 \mathrm{E}-003$ & 1 & $5.256 \mathrm{E}-003$ & 11.72 & $0.0111^{*}$ \\
\hline $\mathrm{X}_{13}$ & 0.039 & 1 & 0.039 & 86.99 & $<0.0001^{*}$ \\
\hline $\mathrm{X}_{13}$ & $7.562 \mathrm{E}-004$ & 1 & $7.562 \mathrm{E}-004$ & 1.69 & 0.2352 \\
\hline Residual & $3.139 \mathrm{E}-003$ & 7 & $4.484 \mathrm{E}-004$ & & \\
\hline Lack of fit & $1.492 \mathrm{E}-003$ & 3 & $4.973 \mathrm{E}-004$ & 1.21 & $0.4144^{* *}$ \\
\hline Pure error & $1.647 \mathrm{E}-003$ & 4 & $4.117 \mathrm{E}-004$ & & \\
\hline Total & 0.082 & 16 & & & \\
\hline
\end{tabular}

The mathematical model of POME treatment optimization was estimated based on the experimental results using Box-Behnken design with the respective coefficients. as given in following equation:

Phenol $=0.69470-0.23663 *$ Dossage adsorbent $+4.68333 \mathrm{E}-003 *$ Contact time content $0.14528 * \mathrm{pH}$ solution $+0.022678 *$ Dossage adsorbent ${ }^{2} \quad$ - 1.25802E$005 *$ Contact time ${ }^{2}+6.50278 \mathrm{E}-003 * \mathrm{pH}$ solution ${ }^{2}-5.37037 \mathrm{E}-004 *$ Dossage adsorbent*Contact time $+0.021944 *$ Dossage adsorbent*pHsolution $1.01852 \mathrm{E}-004 *$ Contact time*pH solution

\subsection{Response Surface Plotting and Optimization of Phenol Responses}

All the plots for investigating the optimization of phenol responses using the Box Behnken design are given in Fig. 1. The studentized residuals is presented in Fig. 1a. From the figure. it is shown that all points were close to the line which indicates that there were no obvious problems with the normality of the design. The values of the studentized residuals were between -3.5 and +3.5 . as shown in Fig. 1b. suggesting a good fit of the model to the response surface. The observed response value was not considered for any value beyond these values. The outlier test for the POME treatment experimental runs clearly showed that all the points were in the range considered. The outlier is figured out in Fig. 1c. Furthermore. the Fig. 1d shows the actual value of the phneol from the 
experimental runs was nearly the same as the value predicted by the model. It indicates a good correlation for the Box-Behnken design model. The same results was also found by Said [6].

The 3D response surfaces graphs were used to illustrate the effects of the interaction between each of the two factors of the dossage of adsorbent. $\mathrm{pH}$ solution and the contact time on performance of phenol as shown in Figure 2.
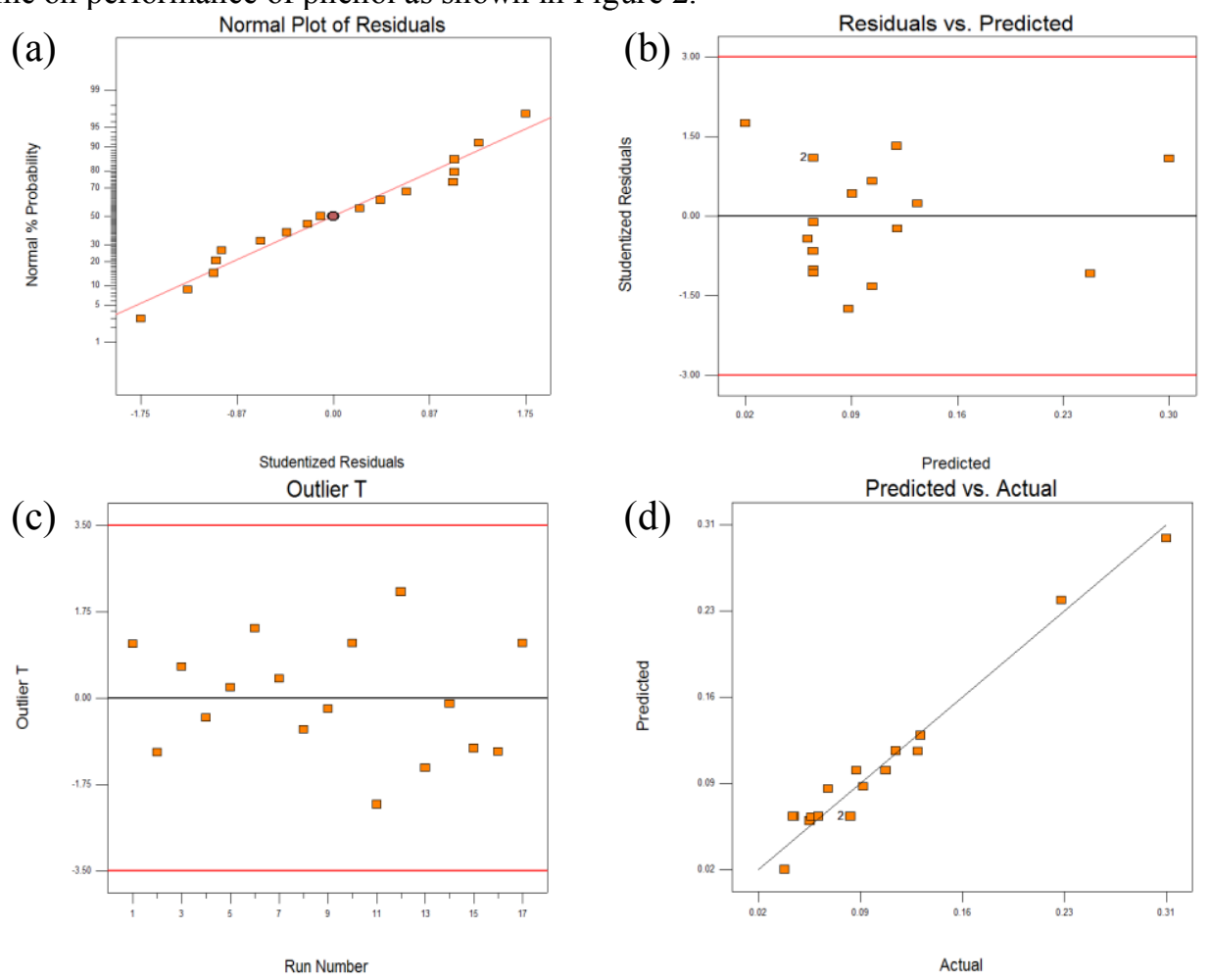

Fig. 1. All diagnostic plots of optimization of phenol:(a) normality.(b) studentized residuals. (c) outlier T. (d) actual (measured) versus predicted
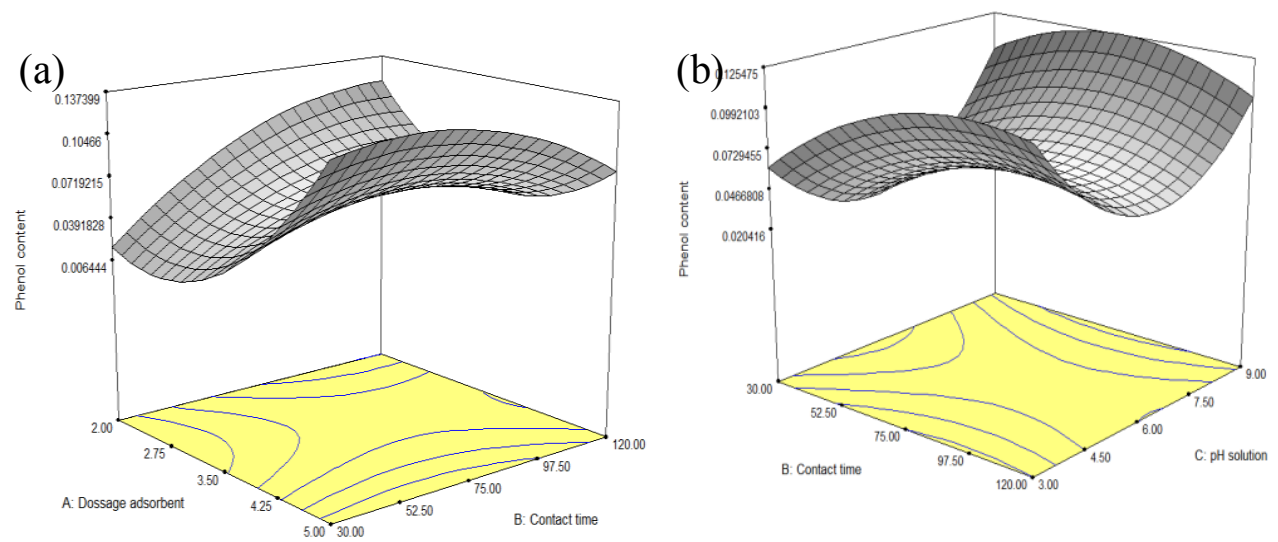

Fig. 2. The 3D surface of Box Behnken model 
From the Fig. 2a. it can be observed that the efficiency of parameter removal was determined by the different condition of each factor. The lowest concentration of phenol was reached as increasing dossage of adsorbent contrary to contact time. This phenomenon was common in all the adsorption process. When the adsorbent dossage increase. it means the active surface of the adsorbent automatically added and attractive force between adsorbent and adsorbate will also increase. The consequency was the adsorbate easily to attaching to the adsorbent surface and passing through the pores [7]. Similar to the previous phenomenon. the phenol values were found to be increase as the contact time increased. It is not surprising when the contact time increased significantly more solid particles can be attached on the surface. This phenomenon is probably due to the small size of phenol makes bigger chance of the small particles in the solution to pass through the bentonite pores [8].

The same phenomenon also happen in Fig. 2b. where longer contact time doesn't affect to the concentration of phenol. $\mathrm{pH}$ has big effect to the phenol content. the phenol value was found to increase as the concentration of POME increased due to the presence of higher concentrations of impurities in the POME solutions. This behaviour may be due to the changing surface properties of impurities in POME with changing $\mathrm{pH}$. At higher $\mathrm{pH}$. the charge of the impurities could be equal to the charge on the surface of the adsorbent. The similarity of these charges leads to Coulombic repulsion between the impurities and adsorbent; thus the impurities do not stick to the adsorbent surface and get trapped in the bulk solution. Conversely. at lower solution $\mathrm{pH}$. the attractive forces between the impurities and surface of the adsorbent are increased and the impurities are capable of easily attaching to the adsorbent surface and passing through the pores. The impurities likely included both solid particles and organic molecules and the existence of organic molecules can be assumed as the phenol value in solution explaining why higher phenol values were observed at higher $\mathrm{pH}[9]$.

\subsection{Model Validation of Optimization Conditions}

Based on desirability option. the simulated figures showed the optimum value of dosage. contact time and $\mathrm{pH}$ were $2.20 \mathrm{mg} / \mathrm{L}$. $70.68 \mathrm{~min}$ and 8.07. respectively. By applying the optimum values. additional experiment was done. The experimental result was $0.0297 \mathrm{mg} / \mathrm{L}$ that much closed to the predicted by the model. i.e $0.0303 \mathrm{mg} / \mathrm{L}$. It proves the Box Behnken design is the great tools in order to obtain the optimum operational conditions and this was attributed to the good interaction between the all selected factors [10].

\section{Conclusions}

In this study. the POME treatment process using Bentonite was optimized by applying the response surface method (RSM) based on the Box-Behnken design. The effects of factors affecting the POME treatment process and the interactions of those factors were estimated by ANOVA. Good correlation coefficients of $\mathrm{R}^{2}=0.9615$ and $\mathrm{R}^{2} \mathrm{adj}=0.9121$ of the predicted model were obtained. The optimum of parameter removal will be achieved when the dosage of adsorbent. concentration of POME and $\mathrm{pH}$ were $2.20 \mathrm{mg} / \mathrm{L} .70 .68 \mathrm{~min}$ and 8.07. respectively. The final value of phenol was 0.0297 . This result supports the validity of the model created by Box-Behnken design and suggests the method is a suitable way for optimizing the conditions of the POME treatment process. 


\section{Acknowledgments}

The author is grateful to Universitas Sriwijaya for supporting funding through the Hibah Unggulan Kompetitif 2018.

\section{References}

1. A.L Ahmad. S. Ismail. S. Bathia. J. Desalination 157 (2003)

2. A. Lante. A. Crapisi. A. Krastanov. P. J. Spettoli. Process Biochemistry 36 (2000)

3. M. Ahmaruzzaman. J. Advances in Colloid and Interface Sci 143 (2008)

4. M.Said. H.A.Hassan. M.T.M.Nor. A.W.Mohammad.Desalination and Water Treatment 57 (2016)

5. A.I. Khuri. J.A. Cornell. Response Surfaces. Design and Analyses. 2nd ed.. Marcel Dekker Inc.. New York. 1996.

6. M. Said. M.M.B.Abbad. S.R.S.Abdullah A.W.Mohammad. International J. Advanced Sci. Eng. Inform. Tech. 7 (2017)

7. L.G. Yan. X.Q. Shan. B. Wen. S. Zhang. J. Colloid and Interface Sci 308 (2007)

8. V.C. Srivastava. M.M. Swamy. I.D. Mall. B. Prasad. I.M. Mishra. Colloids and Surfaces A: Physicochem. Eng. Aspects 272 (2006)

9. S. Yapar and M.Yilmaz. Adsorption 10 (2004)

10. W.T. Mook. M.K. Aroua. M.H. Chakrabarti. C.T.J. Low. P. V. Aravind. N.P. Brandon. Electrochimica Acta 94 (2013) 